Theories \& Applications, the International Edition

Printed Version: (ISSN 2090-5262)

Online Version: (ISSN 2090-5270)

November 2013, Volume 3, No. 3 Pages (94 - 100)

\title{
Effect of Post-Exercise Ingestion of High Glycaemic Index Drink on Glycogenin Activity
}

\author{
Sherine Ahmed Taha*
}

\begin{abstract}
Skeletal muscle can adopt to different chronic metabolic changes, such as regular exercise activities. Tae Bo (Total Awareness Excellence Body Obedience), includes aerobic and high intensity exercises with high synchronization regulatory modules leading to high improved upward and forward capacity, trunk and thigh elasticity, agility, synchronization and performance efficiency. Glycogen is the storage form of carbohydrate degraded to generate ATP during increased energy demand in exercise and re-synthesized during recovery. The initiation of glycogen synthesis is provided by a self-glucosylation of a protein self extracting enzyme glycogenin under the control of insulin and blood glucose levels. Post-exercise high glycaemic index carbohydrates intake favor glycogenin-1 activity. As far as our knowledge, there is no researches investigated blood glycogenin-1 response to Tae Bo exercise either acute or chronic. Thirty female students from the faculty of physical education for girls, Zagazig University, grade two were constituted subjects of this study. They were subjected to a Tae Bo training program for 12 weeks. Their physical measurements and blood glycogenin-1, insulin and glucose were assayed and correlated. Results revealed significant improvement in all physical measurements with increased response of post exercise blood levels in glycogenin-1 and insulin with administration of post-exercise high glycemic index drinks. It is concluded that training Tae Bo program with post exercise high glycemic index carbohydrate intake increase the physical efficiency with improved high performance.
\end{abstract}

\section{Introduction}

$\mathrm{S}^{\mathrm{s}}$ keletal muscle exhibits a high degree of plasticity, have the ability to adopt different chronic metabolic changes, such as chronic exercise activities or various oxygen concentrations.

Tae Bo exercise is a combination of self awareness and control of military skills, the center and power of boxing, charm and rhythm of dance in one aerobic exercise created by Billy Blanks. In aerobics, the tempo of music determines the intensity of exercise, faster tempo intensive work (high impact), and the slow tempo imposes lower intensity exercise (low impact). According to Despić (1996,

* Lecturer at Exercises, Gymnastics, and Motion Expression Department, Faculty of Physical Education for Girls, Zagazig University, Egypt.
1997), Tae Bo word was formed from the initial syllables of two sports - taekwando and boxing. Blanks later explained the name of Tae Bo as (Total Awareness Excellence Body Obedience), and in 1989, it began with a combination of music and the elements of taekwando and boxing, to achieve more intensive training (Milenković and Veselinović 2010).

Tae Bo includes aerobic exercises, it increases the capacity of the heart and lungs, flexibility, it burns calories, it reduces stress, and it strengthens the muscles of the body. These high-intensity exercises are among the cardio vascular exercises, they affect the strength, muscular endurance, flexibility, and they develop general body coordination. Coordination is characterized by the use of muscles or muscle groups that are most appropriate to requested movement. On that occasion, the synchronization higher regulatory 
centers and peripheral parts of the locomotor apparatus is performed (Metikoš et al., 2003).

Glycogen is the storage form of carbohydrate. Most tissues store glucose as glycogen, with the major depots located in muscle and liver. During exercise, muscle glycogen is degraded to generate ATP during increased energy demand, whereas hepatic glycogen is broken down for release of glucose into the bloodstream to supply other tissues. However, recent findings demonstrate that the roles of glycogen metabolism in energy sensing, integration of metabolic pathways, and coordination of cellular responses to hormonal stimuli are far more complex. After exercise (during recovery), glycogen synthesis follows a simple but strictly ordered process, resulting in a complex structure (Melendez et a;., 1999 and Roach (2002).

The initiation of glycogen synthesis is provided by a self-glucosylation of a protein self extracting enzyme glycogenin as oligosaccharide primer, glycogen synthase utilizes UDP-glucose to add glucose molecules by 1-4 linkages, which is the rate-controlling step of glycogen synthesis (Greenberg et al., 2006).

Glycogenin initiates granule formation by the addition of about 7-11 glucose residues to a single tyrosine residue on the apo-protein og glycogenin. To date, two types of glycogenin have been identified: glycogenin-1 and glycogenin-2 (Mu et al., 1997). Glycogenin-1 (42 kDa) content is greatest in skeletal muscle with small amounts located in the liver, whereas glycogenin-2 (66 kDa) is abundant in the heart and liver, with small amounts in the pancreas (Shearer et al., 2005 [A\&B]).

Although it is appreciated that glycogenin-1 is essential for the formation of a glycogen granule, its regulation has rarely been studied in human plasma (author data is there is no any study concerned plasma glycogenin levels), and its fate is unknown in circumstances where glycogen stores decrease. The data available for glycogenin-1 under conditions of changing glycogen concentration are not comprehensive enough to determine whether the protein is degraded during exercise and then newly synthesized during recovery or the protein is conserved and exists as apo- glycogenin-1 and/or is translocated (Wilson et al., 2007).

The glycaemic index categorizes foods containing carbohydrates according to the blood glucose response that they elicit. Carbohydrate foods evoking the greatest responses are considered to be high glycaemic index foods, while those producing a relatively smaller response are categorized as low glycaemic index foods. Post-exercise meals should consist of high glycaemic index carbohydrates. Low glycaemic foods do not induce adequate muscle glycogen re-synthesis compared with high glycaemic index foods of course, the highest glycemic index is glucose. The most concentration absorbed was found to be $0.7 \mathrm{~g} / \mathrm{kg}$ body weight (Peter and Edward, 1997).

In the present study, subjects were subjected to prolonged sub-maximal Tae Bo exercise $(75 \%$ of VO2max) to reduce the muscle glycogen and then glucose drink ingestion were administrated to discover the rate of glycogen re-synthesis during recovery after training program for 12 weeks with these drinks. We tested for changes in plasma glycogenin-1 protein and levels of plasma glucose and insulin levels under these conditions. Also, physical adaptation including upward and forward capacity, trunk and thigh elasticity, agility, synchronization and performance efficiency were investigated and correlated to the program.

\section{Materials and Methods}

\section{Subjects}

Thirty female students from the faculty of physical education for girls, Zagazig University, grade two. Their age was $18 \pm 0.7 \mathrm{yr}$; weight was $63 \pm 3.6 \mathrm{~kg}$; and height was $164 \pm 5.2 \mathrm{~cm}$. They were recruited for the study after completing a medical questionnaire and giving their informed, written consent. All experimental procedures were approved by the Zagazig University Human Research Ethics. Participants were subjected to the first experimental trial, all subjects performed Tae Bo exercise.

\section{Exercise protocol design:}


This study was proposed to investigate the effect of a training program accompanied with post-exercise glucose administration on the adaptation process for glycogen re-synthesis and its effect on some physical parameters improvement including upward and forward capacity, trunk and thigh elasticity, agility, synchronization and performance efficiency. Subjects were subjected to an intense program for 12 weeks at $75 \%$ of $\mathrm{VO} 2$ max for upgraded time started at $1 \mathrm{hr} / 4$ days/ week and increased be five minutes every two weeks to be 90 $\mathrm{min} / 4$ days/week at the end of the program. The Tae Bo exercise session was partitioned into 5 min. for warming up, $50-80$ min for Tae Bo exercise and $5 \mathrm{~min}$ for active cool down. Glucose drink was administrated orally at the end of every exercise bout at $0.7 \mathrm{~g} / \mathrm{kg}$ body weight, followed by a recovery period, after a 12-h overnight fast.

\section{Blood Analyses}

Blood was sampled from an antecubital vein at rest and one hour after the end of the exercise session before and after the training and drink program. Plasma was immediately separated by centrifugation and stored at $-20{ }^{\circ} \mathrm{C}$ for later analysis. Plasma glucose was determined by using an enzymatic colouremetric kit. Plasma insulin and glycogenin-1 were analyzed by using an ELISA kits.

\section{Statistical analysis}

All values reported are the means \pm SD. Data are represented with resting samples and compared post-exercise samples. Mean values for the two experimental conditions were compared by using $\mathrm{t}$ paired sample by using (SPSS V.17) computer designed statistical program. Specific differences were assigned with a significance level of 0.05 .

\section{Results}

In Table (1), there are results of significance difference of arithmetic means of all general physical tests between initial measurements of the female students compared to the posttraining program results.

Table (1)

Measured physical parameters of investigated students before program compared to after program

\begin{tabular}{|c|c|c|c|c|c|}
\hline & Before & After & & & \\
\hline & \multicolumn{2}{|c|}{ Mean \pm SD } & $\mathrm{t}$ & $\mathrm{p}$ & Significance \\
\hline To upward capacity & $25.4 \pm 3.53$ & $41.2 \pm 4.96$ & -24.445 & $<0.001$ & $S$ \\
\hline Forward capacity & $127.5 \pm 9.79$ & $192.5 \pm 12.96$ & -16.194 & $<0.001$ & $\mathrm{~S}$ \\
\hline Trunk elasticity & $27.8 \pm 2.74$ & $34.9 \pm 3.73$ & -11.743 & $<0.001$ & $S$ \\
\hline Thigh elasticity & $32 \pm 3.23$ & $23.9 \pm 4.28$ & 10.371 & $<0.001$ & $\mathrm{~S}$ \\
\hline Agility & $9.85 \pm 0.63$ & $7.5 \pm 0.41$ & 15.667 & $<0.001$ & $S$ \\
\hline Synchronization & $10.25 \pm 0.68$ & $7.95 \pm 0.44$ & 11.500 & $<0.001$ & $S$ \\
\hline Performance efficiency & $3.25 \pm 0.63$ & $6.75 \pm 0.92$ & -23.479 & $<0.001$ & $S$ \\
\hline
\end{tabular}

There are no statistically significant difference results were significantly high in both insulin in any biochemical parameters (glucose, insulin and glycogenin-1) in resting state (pre-exercise) related to the training program. Post-exercise and glycogenin-1 levels after the training program (Table 2).

Table (2)

Comparison between plasma levels of glucose, insulin and glycogenin-1 before program to after program

\begin{tabular}{|c|c|c|c|c|c|}
\hline & Before program & After program & & & \\
\hline & \multicolumn{2}{|c|}{ Pre-exercise (Mean \pm SD) } & t & P & Sig. \\
\hline Glucose $(\mathrm{mg} / \mathrm{dl})$ & $81.6 \pm 3.1$ & $82 \pm 3.33$ & -0.27 & 0.79 & NS \\
\hline Insulin $(\mathrm{umol} / \mathrm{ml})$ & $17.37 \pm 3.62$ & $17.24 \pm 2.84$ & 0.16 & 0.88 & NS \\
\hline Glycogenin-1(pg/ml) & $40.85 \pm 7.98$ & $44 \pm 7.27$ & -0.87 & 0.41 & NS \\
\hline & \multicolumn{7}{|l|}{ Post-exercise (Mean \pm SD) } & t & P & Sig. \\
\hline & $83.2 \pm 4.1$ & $81.2 \pm 3.19$ & 0.50 & 0.63 & NS \\
\hline Glucose $(\mathrm{mg} / \mathrm{dl})$ & $23.63 \pm 3.03$ & $36.96 \pm 5.38$ & -12.25 & 0.01 & $\mathrm{~S}$ \\
\hline Insulin $(\mathrm{umol} / \mathrm{ml})$ & $64.63 \pm 7.9$ & $80.2 \pm 8.52$ & -9.58 & 0.01 & $\mathrm{~S}$ \\
\hline Glycogenin-1(pg/ml) & & & &
\end{tabular}


Acute effect of exercise leads to increased levels of insulin and glycogenin-1 in both before and after the training program while in all cases glucose levels are stable and not changed (Table $3)$.

Table (3)

Comparison between plasma levels of glucose, insulin and glycogenin-1 pre-exercise to post-exercise

\begin{tabular}{|c|c|c|c|c|c|}
\hline & \multicolumn{2}{|c|}{ Before program (Mean \pm SD) } & & & \\
\hline & pre-exercise & post-exercise & $\mathrm{t}$ & $\mathrm{P}$ & Sig \\
\hline Glucose $(\mathrm{mg} / \mathrm{dl})$ & $81.6 \pm 3.1$ & $83.2 \pm 4.1$ & $\begin{array}{c}-0.92 \\
-92\end{array}$ & 0.38 & NS \\
\hline Insulin (umol/ml) & $17.37 \pm 3.62$ & $23.63 \pm 3.03$ & -8.01 & 0.01 & $\mathrm{~S}$ \\
\hline \multirow[t]{3}{*}{ Glycogenin-1(pg/ml) } & $40.85 \pm 7.98$ & $64.63 \pm 7.9$ & -7.14 & 0.01 & $\mathrm{~S}$ \\
\hline & \multicolumn{2}{|c|}{ After program $($ Mean \pm SD) } & & & \\
\hline & pre-exercise & post-exercise & $\mathrm{t}$ & $\mathrm{P}$ & Sig \\
\hline Glucose $(\mathrm{mg} / \mathrm{dl})$ & $82 \pm 3.33$ & $81.2 \pm 3.19$ & 0.50 & 0.63 & $\mathrm{NS}$ \\
\hline Insulin (umol/ml) & $17.24 \pm 2.84$ & $36.96 \pm 5.38$ & -12.25 & 0.01 & $\mathrm{~S}$ \\
\hline Glycogenin-1(pg/ml) & $44 \pm 7.27$ & $80.2 \pm 8.52$ & -9.58 & 0.01 & $\mathrm{~S}$ \\
\hline
\end{tabular}

There was a tendency of correlation between glucose and insulin either pre-exercise or postexercise $(\mathrm{p}=0.08)$.

\section{Discussion}

This study was proposed to investigate effect of Tae Bo training program accompanied by postexercise carbohydrate drink on the adaptation of tissues' post-exercise glycogen re-synthesis and other physical parameters including upward and forward capacity, trunk and thigh elasticity, agility, synchronization and performance efficiency.

Results revealed general improvement in all physical characteristics in the investigated female students. Students in grade two are still untrained well. To upgrade their physical fitness, it is recommended to practice exercise programs for the development of endurance, mobility and coordination. One of these programs is the recreational Tae Bo training model, which develops aerobic endurance, strength, mobility and coordination (Boeva et al.; 2003). Also, Tae Bo workouts lead to the reduction in body mass, circular dimensionality and some subcutaneous fat (Petković et al.; 2007). In addition to influencing on the body in the physical sense, it is it improves mental acuity, self-confidence, locomotor synchronization, self-awareness, and getting to know the basics of different martial arts (Milenković and Veselinović, 2010).

Findings of this study revealed non-significant elevation in plasma glucose in the all investigated stages of the study. Insulin levels were elevated post-exercise either before or after program with highest significant levels after program.

Decreasing muscle glycogen content after exercise may play a role, because the activation of AMP kinase (AMPK) and its associated increases in muscle glucose uptake are affected by glycogen content (Wojtaszewski et al., 2002). During exercise, continued muscle contraction lead to glycogen breakdown with increased extracellular glucose uptake and utilization (Greenberg et al., 2006). Glucose transport into the muscle is increased, correlated acutely with enhanced glucose protein carrier GLUT4 translocation to the plasma membrane (24, 52). According to these mechanisms, glucose remains constant in plasma through all investigation periods.

Glucose uptake in muscle is stimulated by increased blood flow in the absence of insulin (Melendez et al., 1999). Also, muscle contraction stimulates (AMPK), particularly its 2 isoform, which induces translocation of GLUT4 to the plasma membrane and enhances cellular glucose uptake (Kurth-Kraczek et al., 1999). Many studies have provided evidence that the activation of AMPK-2 by muscle contraction depends on exercise intensities. Activity of skeletal muscle AMPK-2 was 3 to 4 fold higher immediately after high-intensity exercise (75\% VO2 max for $60 \mathrm{~min}$ ), whereas no activation was observed after low-intensity exercise (50\% VO2 max for $90 \mathrm{~min}$ ) (Kraniou et al., 2000). Similarly, the effect of exercise intensity on AMPK-2 activity was examined by 20 -min cycle ergometer exercise at low $(40 \%$ 
VO2 max), medium $60 \%$ VO2 max), and high (79\% VO2 max) intensities. AMPK-2 activity increased 5-fold from low to medium intensity, and it increased further from medium to high intensity (Chen et al., 2003). Cycling for $30 \mathrm{~min}$ at a workload requiring $62.8 \%$ of $\mathrm{VO} 2$ max significantly enhanced AMPK-2 activity after 5 min (2-fold), and the activity further elevated after $30 \mathrm{~min}$ (3-fold) of exercise (Stephens et al., 2002). Collectively, at least $60 \%$ of VO2 max as a threshold intensity of exercise may be required to stimulate AMPK-2 activity in human skeletal muscle (Hayashi et al., 2005).

Insulin elevation was found to increase after exercise. Brun et al. (1995) found insulin to increase after a single bout of exercise at $85 \%$ of maximal theoretic heart rate (HR), they reported that glucose effectiveness and insulin sensitivity markedly increased at min 25 after 60-min hard exercise at $85 \%$ of estimated maximum HR that corresponded to about $70-80 \%$ VO2 max. Rheaume et al., (2003) demonstrated insulin elevation at $(70-80 \%$ VO2 max) and Mikines et al., (1998) at $70 \%$ VO2 max and at $(65 \%$ VO2 max). Insulin stimulated recruitment of glucose transporter (GLUT-4) to the plasma membrane and activation of glycogen synthase in muscle are the major mechanisms responsible for the enhanced insulin-stimulated glucose transport and metabolism (Sakamoto and Goodyear, 2002).

The main cause of this study was investigating plasma glycogenin-1 as a precursor for postexercise glycogen resynthesis. Glycogenin-1 was found to be elevated markedly after an hour of exercise with drinking glucose drink. Also, it is more elevated at the end of the program up to double fold of resting levels meaning response to the program with glucose drink.

Wilson et al. (2007) reported that the regulation of GN-1 is poorly understood and has rarely been examined in human muscle. The few studies in humans have suggested that during recovery from prolonged exercise $\mathrm{GN}-1$ is synthesized to facilitate new granule formation and glycogen (especially pro-glycogen) resynthesis (Kraniou et al., 2000 and Shearer et al., $2005[\mathrm{~A} \& \mathrm{~B}])$. To date, there have been no comprehensive examinations of this possibility.
Previous studies revealed a decrease of $40 \%$ in GN-1 activity upon exhaustion (EXH) following prolonged submaximal exercise (Shearer et al., 2005 [A]) but (Shearer et al., 2005 [B]) revealed a more than twofold increase in GN-1 activity during recovery from a prolonged bout of cycling exercise. Together, these two studies suggest that, during prolonged exercise, glycogen granules are degraded, and $\mathrm{GN}-1$ is degraded and then rapidly resynthesized during recovery. Intense exercise bout successfully reduced muscular glycogen by $75-85 \%$ but neither did GN-1 protein decrease, nor did its mRNA increase. Neither, was there an indication of an increase in protein nor mRNA level during recovery, despite a doubling of glycogen concentration by $2 \mathrm{~h}$ of recovery with CHO administration ( $\mathrm{P}<0.05)$. Within $5 \mathrm{~h}$ of recovery, total glycogen levels were resynthesized to be about $80 \%$ of resting levels (Wilson et al., 2007).

GN-1 catalyzes the addition of a single UDPglucose by a C-1-O tyrosyl linkage at amino acid residue Tyr194. Following this initial glucosyl addition to Tyr194, GN-1 adds additional UDP-glucose residues to form an oligosaccharide chain of 7-11 glucosyl units in length, each attached by a1-4 linkages. Once complete, this chain is acted upon by glycogen synthase and phosphorylase. In the case of degradation by glycogen phosphorylase, it is possible that all residues are removed except for the last one attached by Tyr194, whose bond (C1-O tyrosyl linkage) is not accessible by the enzyme (Shearer et al., 2005 [A]).

Elevated plasma GN-1 in this study with adaptation to training program may be first due to increased cell permeability with hypoxia induced by elevated waste products. Second cause may be due to increased white blood cells activities during exercise leading to increased GN-1 production and passing to blood stream (Blom et al., 1986 \&1987). These results need more investigations concerning white blood cells glycogenin-1 mRNA and/or re-investigate previous studies hypothesis of muscular glycogenin-1 translational DNA response.

\section{Refernces}


1. Blom PC, Vøllestad NK, Costill DL. (1986): Factors affecting changes in muscle glycogen concentration during and after prolonged exercise. Acta Physiol Scand Suppl.; 556: 6774.

2. Blom PC, Høstmark AT, Vaage O, Kardel KR, Maehlum S (1987):Effect of different postexercise sugar diets on the rate of muscle glycogen synthesis. Medicine and Science in Sports and Exercise, 19(5):491-496

3. Boeva, B., Angelova, T., Ivanova, V., \& Serafimova, M. (2003). Physical education and sport for ecology directed development of man. Trakia Journal of science, 1(1), 42-43.

4. Brun JF, Guintrand-Hugret R, Bouix O, OrsettiA1995 Influence of short-term submaximal exercise on parameters of glucose assimilation analyzed with the minimal model. Metabolism 44:833-840

5. Chen ZP, Stephens JT, Murthy S, Canny BJ, Hargreaves M, Witters LA, Kemp BE, McConell GK 2003 Effect of exercise intensity on skeletal muscle AMPK signaling in humans. Diabetes 52:2205-2212

6. Drabik, J. (1996). Children \& sports training: How your future champions should exercise to be healthy, fit and happy. Island Pond, VT: Stadion Publiching Company.

7. Despić, D. (1997). Theory of music. Belgrade: Institute for textbooks and teaching aids.

8. Greenberg, CC, Jurczak MJ, Danos AM, Brady MJ. (2006): Glycogen branches out: new perspectives on the role of glycogen metabolism in the integration of metabolic pathways. Am J Physiol Endocrinol Metab 291: E1-E8, 2006

9. Kraniou Y, Cameron-Smith D, Misso M, Collier G, and Hargreaves M. Effects of exercise on GLUT-4 and glycogenin gene expression in human skeletal muscle. J Appl Physiol 88: 794-796, 2000.

10. Kurth-Kraczek EJ, Hirshman MF, Goodyear LJ, Winder WW 1999 5_ AMPactivated protein kinase activation causes GLUT4 translocation in skeletal muscle. Diabetes 48:1667-1671

11. Melendez R, Melendez-Hevia E, and Canela EI. The fractal structure of glycogen: A clever solution to optimize cell metabolism. Biophys $\mathbf{J}$ 77: 1327-1332, 1999.

12. Metikoš, D., Milanović, D., Prot, F., Jukić, I., \& Marković, G. (2003). Theoretical and methodological foundation of coordination development. In D. Milanović \& I. Jukić (eds.), Conditional preparation of sportsmen 2003, (pp. 264-270).

13. Mikines KJ, Sonne B, Farrell PA, Tronier B, Galbo H 1988 Effect of physical exercise on sensitivity and responsiveness to insulin in humans. Am J Physiol 254:E248-E259

14. Milenković, D. and Veselinović, N.: Effect of experimental Tae Bo training model for coordination development of young women. Sport Science 3 (2010) 2: 57- 60

15. Mu J, Skurat AV, and Roach PJ. Glycogenin-2, a novel self-glucosylating protein involved in liver glycogen biosynthesis. J Biol Chem 272: 27589-27597, 1997.

16. Petković, E., Veselinović, N., \& StojanovićTošić, J. (2007). Differences in circular dimensionality and subcutaneous fatty tissue at female subjects included at three months Tae bo exercise program. International scientific conference »Physical activity and health $«$ (pp. 81-86). Belgrade: Faculty of sport and physical education.

17. Peter $\mathrm{W}$ and Edward CR.: Glycaemic Index and Optimal Performance. Sports medicine 23(3): 1997

18. Rheaume C, Waib PH, Kouame N, Nadeau A, Lacourciere Y, Joanisse DR, Simoneau JA, Cleroux J 2003 Effects of intense and prolonged exercise on insulin sensitivity and glycogen metabolism in hypertensive participants. Circulation 108:2653-2659

19. Roach P.J Glycogen and its metabolism. Curr Mol Med 2: 101-120, 2002.

20. Sakamoto K, Goodyear LJ 2002 Intracellular signaling in contracting skeletal muscle. J Appl Physiol 93:369-383

21. Shearer J [A], Graham TE, Battram DS, Robinson DL, Richter EA, Wilson RJ, Bakovic M. Glycogenin activity and mRNA expression in response to volitional exhaustion in human 
skeletal muscle. J Appl Physiol 99: 957-962, 2005.

22. Shearer $\mathbf{J}[\mathrm{B}]$, Wilson RJ, Battram DS, Richter EA, Robinson DL, Bakovic M, Graham TE. Increases in glycogenin and glycogenin mRNA accompany glycogen resynthesis in human skeletal muscle. Am J Physiol Endocrinol Metab 289: E508-E514, 2005.

23. Stephens TJ, Chen ZP, Canny BJ, Michell BJ, Kemp BE, McConell GK 2002 Progressive increase in human skeletal muscle AMPK_2 activity and ACC phosphorylation during exercise. Am J Physiol Endocrinol Metab 282:E688-E694

24. Wilson RJ, Gusba JE, Robinson DL, Graham TE. (2007): Glycogenin protein and mRNA expression in response to changing glycogen concentration in exercise and recovery. Am J Physiol Endocrinol Metab 292: E1815-E1822, 2007.

25. Wojtaszewski JFP, Nielsen JN, Richter EA 2002 Invited review: effect of acute exercise on insulin signaling and action in humans. J Appl Physiol 93:384-392 